Cahiers $d u$ MONDE RUSSE

\section{Cahiers du monde russe}

Russie - Empire russe - Union soviétique et États indépendants

$49 / 4 \mid 2008$

Destins individuels et terreur. Jeunesse dans la société post-stalinienne

\title{
Valerie A. Kivelson, Joan Neuberger, eds, Picturing Russia
}

\section{Christophe Barthélémy}

\section{(2) OpenEdition \\ Journals}

Édition électronique

URL : https://journals.openedition.org/monderusse/7022

DOI : 10.4000/monderusse. 7022

ISSN : $1777-5388$

Éditeur

Éditions de l'EHESS

\section{Édition imprimée}

Date de publication : 28 décembre 2008

Pagination : 847-848

ISBN : 978-2-7132-2197-2

ISSN : $1252-6576$

Référence électronique

Christophe Barthélémy, "Valerie A. Kivelson, Joan Neuberger, eds, Picturing Russia », Cahiers du monde russe [En ligne], 49/4 | 2008, mis en ligne le 24 décembre 2009, consulté le 03 septembre 2022. URL : http://journals.openedition.org/monderusse/7022 ; DOI : https://doi.org/10.4000/ monderusse. 7022

Ce document a été généré automatiquement le 3 septembre 2022.

Tous droits réservés 


\title{
Valerie A. Kivelson, Joan Neuberger, eds, Picturing Russia
}

\author{
Christophe Barthélémy
}

\section{RÉFÉRENCE}

Valerie A. KIVELSON, Joan NEUBERGER, eds, Picturing Russia. Explorations in Visual

Culture. New Haven, CT-Londres : Yale University Press, 284 p.

1 Cet ouvrage collectif - une cinquantaine d'articles d'universitaires anglo-saxons - se propose d'étudier le grand imagier de la Russie. Ce sont des études courtes d'œuvres aux supports très variés: parchemins, porcelaine, icônes, affiches, photographies, monuments, embrassant l'histoire de la Russie, de la principauté de Kiev à la période postsoviétique. Images, supports, producteurs, spectateurs, mais aussi art du regard sont envisagés. Avec tant d'ambition et de variété de supports, il n'est guère étonnant de trouver une telle diversité d'études rassemblées sous le vocable de visual culture. Ce champ de recherche est à la croisée des études culturelles, de l'histoire sociale, de l'histoire de l'art et de l'anthropologie. Les méthodes sont non moins variées, que les rédacteurs de l'ouvrage regroupent en quatre approches. I. La recherche d'aspects inconnus dans les sources écrites; c'est ainsi que Simon Franklin, des traces de cire sur les parchemins tire des enseignements sur la façon dont ils étaient lus. II. Décoder la symbolique dans les sources visuelles, comme Christine Ruane qui voit l'irruption de la modernité en Russie à partir d'une étude de photographies de marchands du XIX siècle. Les deux autres approches abandonnent l'analyse de l'image, se focalisant sur l'évolution du regard à travers les époques et l'expérience de regarder.

2 Le corpus et la variété des auteurs rendent difficile une évaluation globale, néanmoins on peut faire quelques remarques générales. D’abord limitée au domaine religieux et très contrôlée par l'Église orthodoxe, l'image se laïcise avec le règne de Pierre et s'ouvre à des influences étrangères. Le développement des technologies et l'avènement de distribution massive, étudié dans le cadre du lubok par Richard Wortman mais aussi par Stephen 
M. Norris, permettent à une image, de plus en plus autonome de l'État, de se diffuser largement aux quatre coins de l'Empire. La période soviétique est caractérisée par un contrôle politique renforcé et peu de messages. Des invariants demeurent : ainsi on peut rapprocher des éléments de la culture visuelle soviétique d'éléments de la Russie d'avant Pierre. La publicité actuelle n'est pas sans rappeler la contre-propagande pour le capitalisme. La peinture a joué un rôle proéminent dans la construction de l'identité nationale, illustrant les relations de la Russie avec ses protecteurs divins, ses alliés, ses ennemis... On note aussi la permanence des autorités dans la production d'images, que ces autorités soient ecclésiastiques, impériales ou soviétiques.

Certaines études invitent au renouvellement des perspectives ou à l'investigation de nouveaux champs. Mark D. Steinberg voit la photo de quatre ouvriers révolutionnaires en costume bourgeois comme la manifestation d'une transgression subversive de fierté ouvrière. Des photographies d'acteurs de la fin du XIX ${ }^{e}$ siècle sont interprétées par Louise McRenolds comme irruption d'une masculinité plus moderne. Les coupures de 1912 figurant Pierre le Grand (500 roubles), Alexandre III ( 25 roubles), Nicolas I ${ }^{\text {er }}$ (50 roubles) et Catherine (100 roubles) veulent, selon James Cracraft, donner l'impression de stabilité, équivalent à l'or, au moment où le régime tremble sur ses bases. À partir des images de Jehovah dans les années 1920, Robert Weinberg, revisitant des caricatures associant judaïsme à capitalisme, montre la permanence de l'antisémitisme en Russie, y compris aux premières heures du nouveau régime. Elles diffèrent des autres caricatures antireligieuses par le recours aux stéréotypes classiques de l'antisémitisme.

4 Bref, voici un ouvrage utile et intéressant dont il est toutefois malaisé parfois de relier tous les éléments. 